\title{
Corrigendum
}

\section{Corrigendum to "Experimental Study on Strain Reliability of Embroidered Passive UHF RFID Textile Tag Antennas and Interconnections"}

\author{
Xiaochen Chen $\left(\mathbb{D},{ }^{1}\right.$ Aruhan Liu, ${ }^{2}$ Zhigang Wei, ${ }^{2}$ Leena Ukkonen $\mathbb{D}^{1},{ }^{1}$ and Johanna Virkki $\mathbb{D D}^{1}$ \\ ${ }^{1}$ Department of Electronics and Communications Engineering, Tampere University of Technology, P.O. Box 692, \\ 33101 Tampere, Finland \\ ${ }^{2}$ Department of Electronic Engineering, City University of Hong Kong, 83 Tat Chee Avenue, Kowloon, Hong Kong \\ Correspondence should be addressed to Xiaochen Chen; xiaochen.chen@tut.fi \\ Received 22 July 2020; Accepted 23 July 2020; Published 6 October 2020 \\ Copyright (c) 2020 Xiaochen Chen et al. This is an open access article distributed under the Creative Commons Attribution \\ License, which permits unrestricted use, distribution, and reproduction in any medium, provided the original work is \\ properly cited.
}

In the article titled "Experimental Study on Strain Reliability of Embroidered Passive UHF RFID Textile Tag Antennas and Interconnections" [1], the Acknowledgments section should be corrected as follows:

"This research work was supported by the European Commission AdvIOT IRSES Project, Academy of Finland (decision number 294534), TEKES, and Jane and Aatos Erkko Foundation."

\section{References}

[1] X. Chen, A. Liu, Z. Wei, L. Ukkonen, and J. Virkki, "Experimental study on strain reliability of embroidered passive UHF RFID textile tag antennas and interconnections," Journal of Engineering, vol. 2017, Article ID 8493405, 7 pages, 2017. 